\title{
Avrupa Diyetetik Dernekleri Federasyonu (EFAD) Stratejik Planı 2017-2021
}

\author{
European Federation of the Associations of Dietitians (EFAD) Strategic Plan 2017-2021
}

\section{Prof. Dr. Ayla Gülden Pekcan ${ }^{1}$}

\section{Gíriş}

Avrupa Diyetetik Dernekleri Federasyonu (EFAD) 1978 yllında kurulmuştur. EFAD’ın misyonu diyetisyenlerin görev ve sorumluluğu olan sağlıklı beslenmeyi Avrupa'da iyileştirmek, eşitsizlikleri önlemek için üye dernekleri desteklemektir. Türkiye Diyetisyenler Derneği (TDD) 1994 yılında EFAD’a üye olmuştur.

EFAD Stratejik Planı 2017-2021, 2016 yılı Ekim ayında yayınlanmıştır (1). Bu derleme yazı EFAD Stratejik Planı konusunda Türk diyetisyenlere bilgi aktarma amacı ile hazırlanmıştır.

\section{EFAD Stratejik Planı 2017-2021}

Avrupa Diyetetik Dernekleri Federasyonu (EFAD) 2017-2021 yllarını kapsayan 5 ylllı stratejik planın hazırlanmasında gelecek on ylllarda, öngörü doğrultusunda Avrupa'da diyetisyenlerin ve diyetetiğin önemini, beslenme ve sağlığın geleceğini ve EFAD vizyonunun meslek için uygulanmasını dikkate almıştır. Bu amaç doğrultusunda üyesi olan Ulusal Diyetetik Dernekleri'nin, Görevli Komitelerinin, Avrupa Uzman Diyetetik Ağı'nın (European Specialist Dietetic Networks) ve Eğitim Birliği Üyeleri'nin (Education Associate Members) görüşlerini de değerlendirmiştir. Hazırlanan bu strateji, hedeflerin oluşturulmasını, bu hedeflere ulaşabilmek için eylemlerin belirlenmesini ve Avrupa'da sağlıklı beslenmenin iyileştirilmesinde ve eşitsizliklerin azaltılmasında diyetisyenlerin sonuçları nasıl ölçerek değerlendirebileceklerini içermektedir.
Gelecek ylllarda Avrupa'nın ve toplumlarının karşılaşacağı zorluklar ve olumsuzluklar beslenme durumunu ve sağlık üzerine etkisini, diyetisyenin de görev ve sorumluluklarını etkileyecektir.

Buolumsuzluklarsadece diyetebağlıkronikhastalıklar ile akut hastalıkların yükünü içermeyecek bunun dışında, enerji kaynaklarının azalmasını, demografik değişiklikleri, sürdürülebilir besin kaynaklarında iklim ve çevresel değişikler ile değişimleri ve teknolojik gelişmelerin etkisini içerecektir. Avrupa Komisyonu raporu “Küresel Avrupa 2050"de Smits (2), gelecekte karşılaşacağımız değişiklikler ile "mesleklerin olağan hali bir seçenek olamayacak: şu andaki politika çerçevesinde yapılacak küçük uyarlamalar, artımlı değişiklikler, görevi yerine getiremeyecek” vurgusunu yapmaktadır. Bu demektir ki EFAD, aynı zamanda Avrupa'da diyetisyenler ve diyetetik, değişimi kabul ve taahhüt etmelidir. Şu anda stratejik plan sadece 5 yllı kapsadığı için, düşüncelerimizde yer alan gelecekle ilintiyi sağlamaya yardımcı olmaktadır.

Klug (3) 2012 yılında, çalışanların işe alımında ve çalışmanın sürdürülmesinde güçlüklere bağlı olarak sağlık profesyonellerinin sayısında azalmanın olacağını öngörmüştür. $\mathrm{Bu}$ durum diyetetik profesyonelleri için daha fazla interdisipliner ve özerk çalışma olanağı sağlamaktadır. EFAD eğitici (diğer sağllk personeline, toplu beslenme hizmeti verenlere, ailelere, işverene vd.), araştırmacı ve sağlık profesyoneli liderleri olarak, diyetisyenlerin 
görevlerinin artacağını öngörmektedir.

Sağllkta yeni bakım hizmet modelleri gerekmektedir ve tekli müdahalelerden çoklu müdahale paketlerine yönelme sağlık sistemi sunumu gerçeğini destekleyecek ve etkinliği geliştirecektir.

Diyetisyenler daha fazla maliyet yarar/etkililik analizlerinde yer alacak ve tedaviye karşılık koruyucu yaklaşımların dengelenmesinde artan önemi destekleyici olacaktır.

Diyetisyenler sağlık hizmetleri, sanayi ve toplumda hizmetlerin yürütülmesi sistemleri arasında artan boyutta görev alacaktır. Sağlık kazanımlarının arttırılmasının etkin yolları, hem mesleki hem de besin ve beslenme politikalarının sağlık, ulaşım ve su gibi politikalarla birleştirilmesi doğrultusundaki çalışmalarla değerlendirilecektir.

Diyetisyenler besin ve beslenme ile ilintili teknolojik ve diğer hizmetlerde yenilikleri başlatacak, yönetecek ve kullanacaktır. Yenilikler büyük hızla devam edecek ve ekonomik, sağllk ve sosyal gelişme üzerinde doğrudan etkisi olacaktır. Yaşam boyu sağlığın geliştirilmesi aktiviteleri (örneğin gıda güvenliği yaklaşımları varlığında artık kaybının azaltılması ve sağlık hizmeti sistemleri çağrısının azaltılması gibi), diyetisyenlerin bilgi teknolojisini ve iletişimi kullanma ve pratik uygulamaları ile birleştirmeleri sonucu artacaktır.

$\mathrm{Bu}$ diyetetik aktivitenin geleceğe yansitılması bir temeldir ve tüm diyetetik profesyonelleri için kanıta dayalı uygulamada elzem gerekliliktir. Diyetisyenler Avrupa'daki insanlar için beslenme durumunun iyileştirilmesi ve eşitsizliklerin azaltılmasında hem uygulamaları hem de akademik temelli araştırmaları ile bilimsel kanıtlara katkıyı artıracaktır.

Yükseköğrenim ve üniversiteler özellikle ders programlarını revize ederek buna katkıda bulunacak, yaşam boyu öğrenim olanaklarını artıracak ve teknoloji, maliyet etkililik analizli sağlık hizmeti sunumunda değişiklikleri destekleyen araştırmalar yapacak ve sürdürülebilir diyetlerin daha fazla önemsenmesini sağlayacaktır.
Gelecekte diyetetik, teknolojiyi iletişim ve veri toplamanın önemli gereği olarak kullanarak maliyet etkililik analizli sağlık hizmetinde katkı sağlayacak, korunma, birincil (primer)/toplum sağlığı hizmetleri ve beslenme eğitimlerine katılımı artıracaktır.

Dernekler ve Yüksek Öğrenim Kurumları bu güçlükleri karşılayabilmek üzere diyetisyenleri nasıl hazırlayacaklarını ve güçlendireceklerini düşünmek zorundadır. Örneğin çok yönlü işyerlerinde çalışmak, teknolojiyi kullanarak yeniliklere öncülük yapmak, verilerin toplanması ve analiz edilmesinde temel görevlerini anlamak, besin ve beslenmeyi ilgilendiren politikalarda değişikliklere katkı sağlamak gibi.

Gelecekteki bu senaryolarda üç önemli alanda görev alan diyetisyenlerin karşılaşacakları güçlükler şunlardır:

- Toplu beslenme hizmetleri (kurum beslenmesi) diyetisyeni toplumsal değişikliklere bağlı olarak gelişen yeni ve çeşitli mekanlarda artarak süren tüketimi sürdürülebilir ve sağlıklı besin sunulması doğrultusunda etkileyebilecekleri için, toplum sağlığında liderlik görevi almalıdır.

- Klinik diyetisyenler maliyet-etkililiği sağllk bakım kaynaklarının kullanımında göstermelidir. Diyetisyenler sağlık ekibinde yer alarak, daha özerk olarak da klinik ve ulusal sağlık hizmetlerinde çalışarak liderlik görevi almalıdır.

- Toplum sağlığı diyetisyeni toplum sağlığında, beslenme eğitiminde, teknolojik yeniliklerde ve sağlık kaynaklarının yönetiminde liderlik görevi aldıkları için yaşam sürecinde sağlığı geliştirme aktivitelerinde maliyet-etkililikte güçlüklerle karşılaşacaktır.

Diyetisyenler ve diyetetik sağlığı iyileştirmek üzere hizmet sağladığı için gelecekte diyetisyenlere talep artacaktır.

\section{EFAD'ın Avrupa'da Stratejik Görevi ve Planı}

EFAD Avrupa genelinde diyetisyenleri ve diyetetiği geliştirmek üzere çalışmaktadır. Avrupa diyetisyenleri için EFAD’ın vizyonu ve değerleri sürdürülmektedir 
ve erişim http://www.efad.org/aboutefad/5191/7/0/80 adresinden sağlanabilir.

Vizyon: EFAD, ulusal diyetetik dernekleri ve diyetisyenler beslenme ve diyetetik alanında liderler olarak tanınmıştır (onanmıştır). EFAD beslenme durumunu iyileştirmek, sosyoekonomik sağllk eşitsizliklerini azaltmak ve ekonomik refaha katkı vermek için ortaklıklara devam etmeye ve büyütmeye devam edecektir.

Vizyona erişmek için EFAD yüksek kalitede diyetetik eğitimini, profesyonel uygulamayı, araştırma yapma aktivitelerini ve ortaklığı desteklemektedir.

2017-2021 için EFAD Stratejisi sınırlılıkları firsatlarla karşılamaya yöneliktir.

- Üyeler EFAD ile ortak çalışarak kanıta dayalı uygulama yapma ve mesleki gelişime önem vererek diyetetiğin ve diyetisyenlerin profilini ve kalitesini arttırmak için çalışmaktadır.

- EFAD işbirliği, ortaklık ve diğer unsurlarla birlikte Avrupa'nın gereksinimlerini karşlamak üzere diyetisyenleri hazırlamaktadır.

- EFAD'in hedefi uluslararası, Avrupa ve yerel düzeyde daha sağllklı besin ve beslenme ile sürdürülebilir ekonomik ve sosyal açıdan sağlıklı toplumdur.

\section{EFAD 2017-2021: Stratejik Amaçları}

Amaç 1: Avrupa düzeyinde beslenme ve diyetetiği geliştirmeye destek veren paydaşlar ${ }^{1}$ arasında işbirliği oluşturmak

Bu ne demek? EFAD ve tüm üyeleri anahtar paydaşlarla Avrupa/Uluslararası Ağların üretken üyelikleri aracilığıyla beslenme ve diyetetik ile diyetisyenleri desteklemek için çalışacaktır.

\section{Hedefler:}

a) EFAD sağlıklı beslenmeye ilgiyi ve karşılıklı

${ }^{1}$ EFAD paydaşlarl: EFAD üye dernekleri ve onların üye diyetisyenleri, sağllk, eğitim ve çalışma bakanlıklarl, diğer sağlık profesyonelleri, diyetetik hizmet kullanıcıları (hastalar), işverenler, gıda sanayi, sivil toplum örgütleri yararları konularında işbirliğini sağlamak için stratejik ortaklıklar ve ilişkiler geliştirmek,

b) EFAD beslenme ve diyetetiği geliştirmek üzere politika önermek ve paydaşlarla çalışmak,

c) Araştırma ortaklıklarını ve işbirliğini önemsemek ve geliştirmek.

Amaç 2: Esnek, yenilikçi ve deneysel olabilen yaklaşımlarla mesleği sürekli yükseltmek

$\mathrm{Bu}$ ne demek? Değişen görevler diyetisyenler için Yüksek Öğrenim, mesleki araştırmalara odaklanma, EFAD’ın liderliği ve komitelerinin açık olması, değişikliği tahmin etmesi ve yeni yollarla sorun çözmesi demektir.

\section{Hedefler:}

a) EFAD, komiteleri ve üyeler değişimi tahmin eder ve mesleğin amaca hizmet ettiğinden emin olarak yanıt verir, toplumun gereksinimlerini karşılayan hizmetlerin sürdürülebilir kalitesini sağlar.

b) EFAD, Ulusal Diyetetik Dernekleri ve Eğitim Ortakları sistematik sorgulama ile kanita dayalı uygulamayı ve bilgi oluşturmayı sağlar.

Amaç 3: Avrupa'da bilgi değişimini destekleyen ve EFAD'nn sürdürülebilirliğine öncülük eden sistem geliştirir.

$\mathrm{Bu}$ ne demek? Meslek konusunda veri toplanması ve paylaşılması (sürveyans) diyetisyenlerin sağlığa katkısının tam olarak anlaşılması, daha ileri büyüme ve gelişmeyi destekleyecek diyetetik hizmetleri için talebin arttırılmasında diyetisyenlere ve paydaşlara yardımcı olacaktır.

\section{Hedefler:}

a) EFAD bilginin toplanması, analizi ve değişimi için güvenli ve şeffaf yöntemler geliştirir.

b) EFAD Avrupa'da diyetisyenleri ve diyetetiği geliştirmek için uygun iletişim yolları seçer ve kullanir.

c) EFAD Avrupa'da diyetisyenler için temel söz hakkı (ses) olmada sürdürülebilirliği planlar. 


\section{Stratejik Amaçların Uygulanması ve Hedeflere Erişim}

Avrupa ve küresel güçlükler gelecek ylllarda diyetisyenleri ve diyetisyenlerin görevlerini etkileyecektir. Bu plan geleceğe bakma ve güçlüklerin karşılanmasında temel çalışma sunmakta, aynı zamanda ylllık süreçte mesleğin gereksinimlerine duyarlı kalmaktadır.

Her yll EFAD, Komiteler ve Avrupa Sürdürülebilir Gelişme Ağı (European Sustainable Development Network-ESDN) hedeflere erişmek için çalışma planları hazırlar. Hedeflere erişim sadece EFAD'ın Komitelerine bağlı olmayıp, ESDN ve Eğitim Dernekleri'ne ve aynı zamanda Ulusal Diyetetik Dernekleri'ne bağlıdır. EFAD Yönetim Kurulu çalışma planlarının dikkatli yönetiminden emin olmak için çok çalışacak ve ortakları ile Stratejik Plan hedeflerini karşılamak için çalışacaktır.

Amaçlara ve hedeflere erişim raporu da her zaman olduğu gibi sunulacak ve Ylllık Rapor ve toplantı sonuçları EFAD internet adresinde yayınlanacaktır.

\section{Ek 1: EFAD’ın sürdürülebilir ve rekabetçi olmada olumlu yönleri}

\section{EFAD'ın en iyi olduğ u alanlar nedir?}

- Yayımcilık

- Avrupa-diyetisyenler ağı + uluslararası (35000 üzeri diyetisyen, 9000 üzeri öğrenci diyetisyen ve 37 Yüksek Öğrenim Kurumu)

- Politikacılar, sağlık profesyonelleri, sivil toplum örgütleri

- Avrupa'da diyetetik uzmanlığı pozisyonlarının geliştirilmesi

- İnsan sağlığını, besin ve beslenmeyi etkileyen konularda, diyetetikle ilintili konularda diyetetik uzman görüşü sağlanması

- Diyetetik uygulamalarının ve etkinliğinin sürveyansı

- Mesleğin geliştirilmesi için rehberlik sağlanması

\section{EFAD'ın benzersizliği nedir?}

- EFAD ulusal diyetetik dernekleri, beslenme ve diyetetik eğitimi veren Yüksek Öğrenim Kurumları için Avrupa-çapinda tek kuruluştur.

- EFAD 35000 üzerinde diyetisyeni ve 9000 üzerinde öğrenci diyetisyeni temsil etmektedir.

EFAD'ın diğer kuruluşlardan potansiyel olarak daha iyi yapabileceği nedir?

- Avrupa düzeyinde ki paydaşlarda diyetetik mesleğini temsil etmek

- Avrupa kuruluşları (Avrupa Komisyonu, Avrupa Parlamentosu, Avrupa Gida Güvenliği Otoritesi, Dünya Sağlık Örgütü, Gıda Tarım Örgütü)

- Sivil Toplum Örgütleri (EFPC-European Forum for Primary Care, EPHA- European Public Health Alliance, ENHA-European Nutrition for Health Alliance)

- Gida sanayi

- Medya

- Avrupa Ulusal Diyetetik Dernekleri, Yüksek Öğrenim Kurumları ve diğer kuruluşlarla işbirliğinde birleşik güç oluşturmak

- Avrupa kılavuzlarını geliştirmek ve yerleştirmek, Avrupa'da diyetetik mesleğinin gelişimini izlemek

- Eğitim

- Yaşam boyu öğrenme

- Kanita dayalı uygulama

- Güvenilir ve kaliteli uygulama

- İleri (gelişmiş) uygulama

- Diyetisyenler ve diğer meslekler arası farkı anlama

\section{KAYNAKLAR}

1. European Federation of the Associations of DietitiansEFAD Strategic Plan 2017-2021 October 2016. Available at: http://www.efad.org/media/1057/strategic_plan_20172021.pdf. Accessed: November, $15^{\text {th }} 2018$.

2. Smits RJ. Director-General for Research and Innovation European Commission in writing in 'Global Europe 2050. 
3. https://ec.europa.eu/research/social-sciences/pdf/ policy_reviews/global-europe-2050-report_en.pdf

4. The Knowledge Future: Intelligent policy choices for
Europe 2050.

5. http://ec.europa.eu/research//pdf/publications/ knowledge_future_2050.pdf 